\title{
Detection of Trypanosoma cruzi DNA within Murine Cardiac Tissue Sections by in Situ Polymerase Chain Reaction
}

\author{
Joshua E Lane, Rodrigo Ribeiro-Rodrigues*, Danyvid Olivares-Villagómez**, \\ Cindy L Vnencak-Jones***, Thomas L McCurley***, Clint E Carter**/+
}

\begin{abstract}
Section of Dermatology, Department of Medicine, The Medical College of Georgia, Augusta, GA, USA *Núcleo de Doenças Infecciosas, Departamento de Patologia, Universidade Federal do Espírito Santo, Vitória, ES, Brasil **Department of Biology ***Department of Pathology, Vanderbilt University, PO Box 1812-B, Nashville, Tennessee 37235, USA
\end{abstract}

The use of in situ techniques to detect DNA and RNA sequences has proven to be an invaluable technique with paraffin-embedded tissue. Advances in non-radioactive detection systems have further made these procedures shorter and safer. We report the detection of Trypanosoma cruzi, the causative agent of Chagas disease, via indirect and direct in situ polymerace chain reaction within paraffin-embedded murine cardiac tissue sections. The presence of three T. cruzi specific DNA sequences were evaluated: a 122 base pair (bp) sequence localized within the minicircle network, a 188 bp satellite nuclear repetitive sequence and a 177 bp sequence that codes for a flagellar protein. In situ hybridization alone was sensitive enough to detect all three T. cruzi specific DNA sequences.

Key words: in situ polymerase chain reaction (PCR) - indirect in situ PCR - direct in situ PCR - Trypanosoma cruzi murine cardiac tissue

Trypanosoma cruzi is a protozoan hemoflagellate and etiological agent of Chagas disease (Brener 1973, Tanowitz et al. 1992). Five to 20 years after infection, 30 to $40 \%$ of infected patients may develop cardiomyopathy and/or megaesophagous/megacolon (Prata 2001). Parasitism is often undetectable by routine microscopic observation of tissue sections. The period during which patients remain asymptomatic along with the virtually undetectable parasites in tissues suggests autoimmune processes or hypersensitivity for the pathophysiology. However, Tarleton et al. (1997) reported a lack of autoimmune-type rejection for inflammatory response in neonatal hearts transplanted into mice chronically infected with $T$. cruzi. Olivares-Villagomez et al. (1998) analyzed T. cruzi specific DNA sequences using fluid phase polymerase chain reaction (PCR) and demonstrated that the quantity of $T$. cruzi DNA in the hearts of chagasic patients correlates with cardiomyopathy but may not be associated with inflammatory foci. Palomino et al. (2000) attempted to associate the presence of parasite antigens with histopathologic lesions found in affected tissues from 12 chronic chagasic cardiomyopathies. They reported that at least 1 of 26 regions of each heart demonstrated immunohistochemical reactivity for T. cruzi antigens. However, no correlation between antigen concentration and the intensity of inflammatory foci was established. Thus far, it is unclear whether such cardiomyopathy requires the per-

${ }^{+}$Corresponding author. Fax: 615-343-0336. E-mail: Clint.E.Carter@Vanderbilt.Edu

Received 12 July 2002

Accepted 31 January 2003 sistence of the parasite during the chronic phase or the high parasitemia present during the acute phase is sufficient to trigger progression of the disease (Brener \& Gazzinelli 1997).

In situ hybridization (ISH) with non-radioactive oligonucleotide probes has proven to be an effective method for detecting a multitude of mRNA and DNA sequences (Larsson \& Hougaard 1993). While ISH is effective, the addition of in situ PCR improves sensitivity. Two methods of in situ PCR (indirect and direct) have been used to detect a variety of target sequences (Nuovo 1994). The indirect method utilizes in situ amplification of the target sequence followed by hybridization with a labeled oligonucleotide probe, and the direct method utilizes in situ amplification with labeled deoxynucleotides present within the PCR mixture. In the direct method, incorporation of the label during the elongation phase eliminates the need for subsequent hybridization. We previously described ISH to target three genes in order to identify T. cruzi within cardiac tissue (Lane et al. 1997). This yielded a highly specific and sensitive method of detecting T. cruzi in tissue.

In the present study, we compared two techniques to detect T. cruzi in cardiac tissue. Both indirect and direct in situ PCR were used to detect three T. cruzi-specific DNA sequences in paraffin-embedded sections of infected murine cardiac tissue. These included a minicircle sequence (MCS), a repetitive sequence (RS) and a flagellar protein sequence (FPS). The MCS is localized within the kinetoplast minicircles and represents approximately 120,000 copies per parasite (Degrave et al. 1998). The RS gene is a highly repetitive DNA sequence that represents approximately $9 \%$ of the total parasite genome (Moser et al. 1989). The FPS represents a smaller sequence within the open reading frame of a $160-\mathrm{kDa}$ protein found on the 
parasite's surface overlying the flagellum (Van Voorhis \& Eisen 1989, Van Voorhis et al. 1991).

T. cruzi (Brazil strain) infected C3H mice were sacrificed 30 days post-infection. The hearts were removed and embedded in paraffin. Primers and digoxigenin-labelled oligonucleotide probes used have been previously described (Lane et al. 1997). Primers and probes specific for MCS, RS and FPS used in this study allowed detection of $0.167,0.24$, and 2.4 amastigote DNA equivalents, respectively (Lane et al. 1997).

In situ PCR was performed as described previously (Nuovo 1994, Lane et al. 1997). To confirm the presence of $T$. cruzi amastigotes in the tissue, sections were stained with hematoxylin and eosin (H/E) and viewed under the microscope (Fig. 1). Sections for in situ PCR were treated with pepsin $(2 \mathrm{mg} / \mathrm{ml})$ for $30 \mathrm{~min}$ at room temperature followed by inactivation with $0.1 \mathrm{M}$ Tris- $\mathrm{HCl}, 0.15 \mathrm{M} \mathrm{NaCl}$ (pH 7.5) for 3 min at room temperature. Fifty microliters of the PCR mixture (20 mM Tris- $\mathrm{HCl}, \mathrm{pH} 8.4,50 \mathrm{mM} \mathrm{KCl}, 1.5$ $\mathrm{mM} \mathrm{MgCl} 2,200 \mu \mathrm{M}$ of each dNTP, $0.05 \%$ bovine serum albumin, $2.5 \mu \mathrm{M}$ of each primer pair and 6 units of Taq DNA polymerase) were added to pre-warmed tissue sections at $70^{\circ} \mathrm{C}$. Slides containing tissue sections were incubated at $94^{\circ} \mathrm{C}$ for $3 \mathrm{~min}$ and then 30 cycled at $94^{\circ} \mathrm{C}$ for 1 $\min$ and $55^{\circ} \mathrm{C}$ for $2 \mathrm{~min}$. Sections were then post-fixed in $100 \%$ ethanol for 2 min and air-dried for 1 min followed by ISH (7.5\% dextran sulfate, 2 X SSC $(150 \mathrm{mM} \mathrm{NaCl}, 150 \mathrm{mM}$ Sodium Citrate, $\mathrm{pH}$ 7.0), $2 \mu \mathrm{g} / \mathrm{ml}$ of digoxigenin-labeled oligonucleotide probe). Tissue sections were denatured at $95^{\circ} \mathrm{C}$ for $5 \mathrm{~min}$ and hybridized at $42^{\circ} \mathrm{C}$ for $18 \mathrm{~h}$. The post-hybridization wash included serial washes with SSC (Boshoff et al. 1995). Detection was performed using alkaline phosphatase-labeled anti-digoxigenin-antibodies $(1: 50)$ for $1 \mathrm{~h}$ at $37^{\circ} \mathrm{C}$. Unbound antibodies were removed with two washes of $0.1 \mathrm{M}$ Tris- $\mathrm{HCl}, 0.1 \mathrm{M} \mathrm{NaCl}(\mathrm{pH} 9.5)$

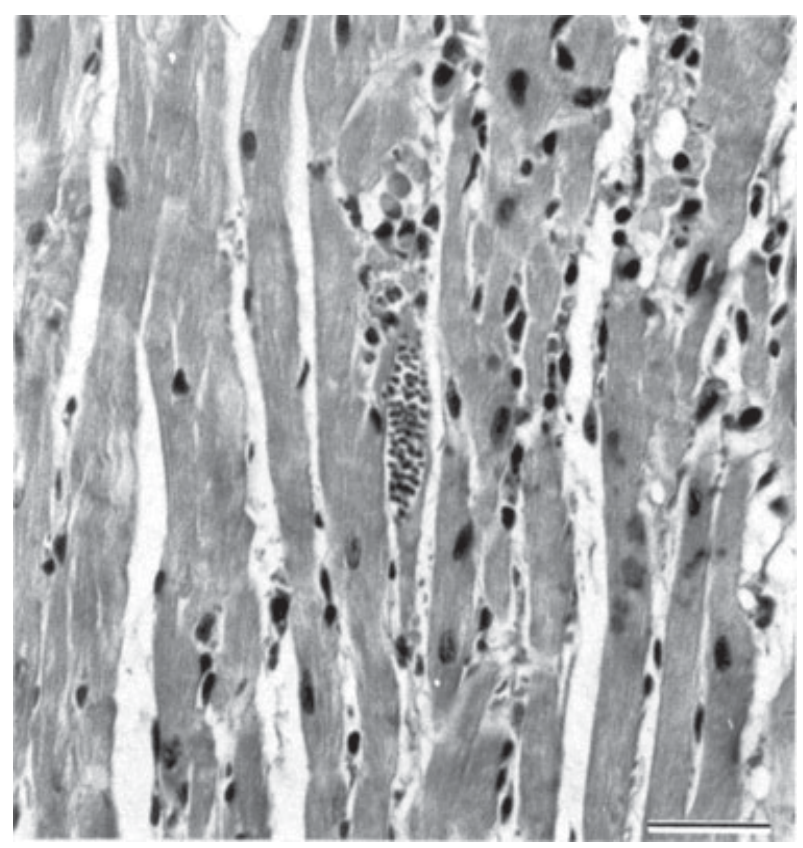

Fig. 1: hematoxylin and eosin-stained section of a Trypanosoma cruzi amastigote nest within infected murine cardiac tissue. Bar $=$ $40 \mu \mathrm{m}$ for $3 \mathrm{~min}$ at $37^{\circ} \mathrm{C}$. Substrate (5-bromo-4-chloro-3-indolyl phosphate/nitro blue tetrazolium) was added for $10 \mathrm{~min}$ at room temperature. Endogenous alkaline phosphatase activity was blocked with levamisole endogenous alkaline phosphatase inhibitor $(0.2 \mathrm{mM})$. Negative controls included no Taq DNA polymerase and no oligonucleotide probe.

The PCR mixture for direct in situ PCR was similar to that described for the indirect in situ mixture, except that $10 \mu \mathrm{M}$ digoxigenin-11-dUTP was used, thus omitting subsequent hybridization. Sections were denatured at $94^{\circ} \mathrm{C}$ for $3 \mathrm{~min}$ and subjected to 20 cycles at $94^{\circ} \mathrm{C}$ for $1 \mathrm{~min}$ and $55^{\circ} \mathrm{C}$ for $2 \mathrm{~min}$. Detection of incorporated digoxigenin-11dUTP was carried out as described above. Negative controls for direct in situ PCR included PCR mixtures without Taq DNA polymerase, primers or digoxigenin-11-dUTP. To ensure that $T$. cruzi was present within cardiac tissue, sections were randomly selected, stained with $\mathrm{H} / \mathrm{E}$ and viewed under the microscope. Amastigote nests were observed in tissue samples examined (Fig. 1).

Indirect in situ PCR allowed detection of T. cruzi amastigotes via three sequences (MCS, FPS and RS) but with different signal strengths. An intense signal was consistently obtained with MCS primers and probes. A strong signal was observed with MCS even when hybridization was used without PCR (Fig. 2a). Detection of FPS was less intense, while a weak and inconsistent signal was obtained for RS (Fig. 3). Controls without Taq DNA polymerase were consistently positive (i.e., hybridization alone) (Fig. 2a) and there was no decrease in the hybridization signal with either MCS or RS probes when Taq DNA polymerase was included or excluded. A weak hybridization signal was observed in FPS control slides (i.e., hybridization following PCR without Taq DNA polymerase in the PCR mixture). This weak signal was significantly enhanced when the PCR mixture contained Taq DNA polymerase (i.e. increased hybridization signal with amplification) (Fig. 3a, 3b). Negative controls for MCS, FPS and $\mathrm{RS}$ without the addition of oligonucleotide probes showed no hybridization signal (Fig. 2b).

All three sequences were detected with direct PCR. A signal was consistently obtained with MCS; however, amplification of RS and FPS yielded weak and inconsistent signals. No signal was found with negative controls containing neither DNA polymerase nor digoxigenin-11dUTP. Negative controls lacking primers showed a consistent weak background signal, which appeared to be localized to the parasite.

Parasitism in T.cruzi infected tissues is often undetectable by direct microscopic observation and/or immunohistochemistry. Detection of DNA and RNA sequences using PCR has become an increasingly useful technique for the diagnosis of pathogens and parasites. Unlike liquid phase PCR, in situ detection allows precise localization of target sequences within tissue sections. In a previous report we demonstrated the efficacy of ISH to detect $T$. cruzi within cardiac tissue (Lane et al. 1997).

The MCS was consistently detected with in situ PCR even when ISH was performed without amplification. Indirect PCR performed prior to hybridization did not significantly increase the ISH signal for MCS. The high 

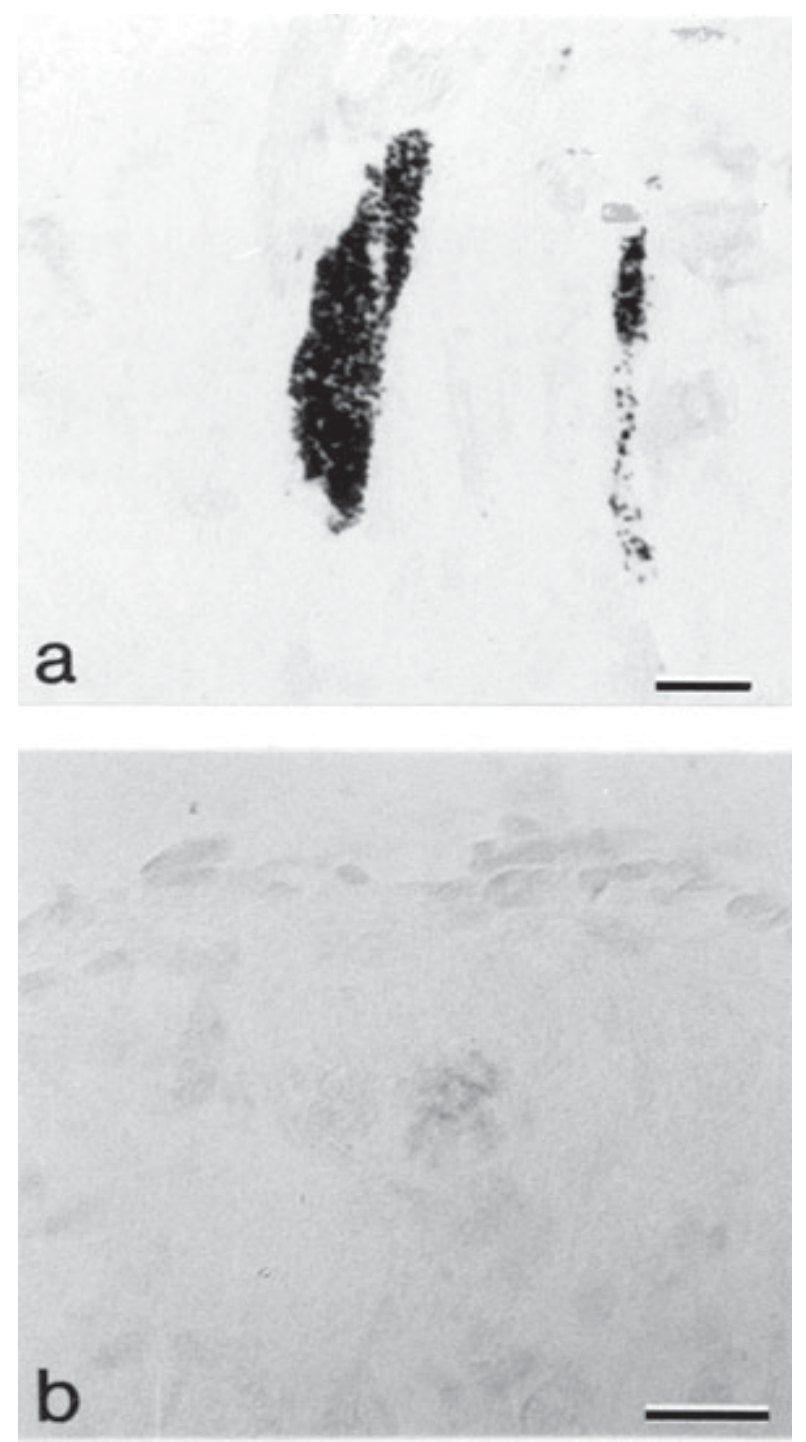

Fig. 2: indirect in situ polymerase chain reaction (PCR) of minicircle sequence with Trypanosoma cruzi amastigote nest in infected murine cardiac tissue. a: control for indirect in situ PCR (Taq DNA polymerase omitted); b: control for indirect in situ PCR (digoxigeninlabeled oligonucleotide probe was omitted). Bars $=40 \mu \mathrm{m}$

copy number of this sequence may explain the intensity of the ISH signal without prior amplification (Degrave et al. 1998). In addition, topological constraints involved in the physical organization of minicircles within the kinetoplast may inhibit efficient amplification (Chen et al. 1995). Our results confirm previous data demonstrating that MCS is consistently found in myocardial tissue from chagasic patients with cardiomyopathy using either fluid phase or in situ PCR followed by hybridization (Lane et al. 1997, Olivares-Villagomez et al. 1998).

The RS represented the least consistent sequence to detect. Olivares-Villagomez et al. (1998) reported that while MCS was detected in $100 \%$ of the samples tested, RS was detected in $37.5 \%$ with liquid phase PCR. OlivaresVillagomez et al. (1998) observed FPS in 2\% of inflammatory foci tested; however, we consistently detected FPS using the indirect in situ PCR method. As with MCS, detection of FPS was possible when hybridization was performed without prior amplification.

In situ PCR incorporation of digoxigenin-11-dUTP is primer-elongation dependent and may provide an alternative to test for sequence specific amplification. With direct in situ PCR, a strong signal was consistently obtained for MCS but only weakly and inconsistently for FPS and RS. As direct in situ PCR requires less steps, it could be considered more convenient. However, in addition to the complications discussed for the indirect method, there is support to confirm the non-specific incorporation of the digoxigenin-labeled nucleotides with direct in situ PCR, which may compromise its use (Komminoth et al. 1992, Komminoth \& Long 1992, Sallstrom et al. 1993). While restricted to amastigote nests within murine cardiac tissue, PCR controls without primers did yield a weak signal
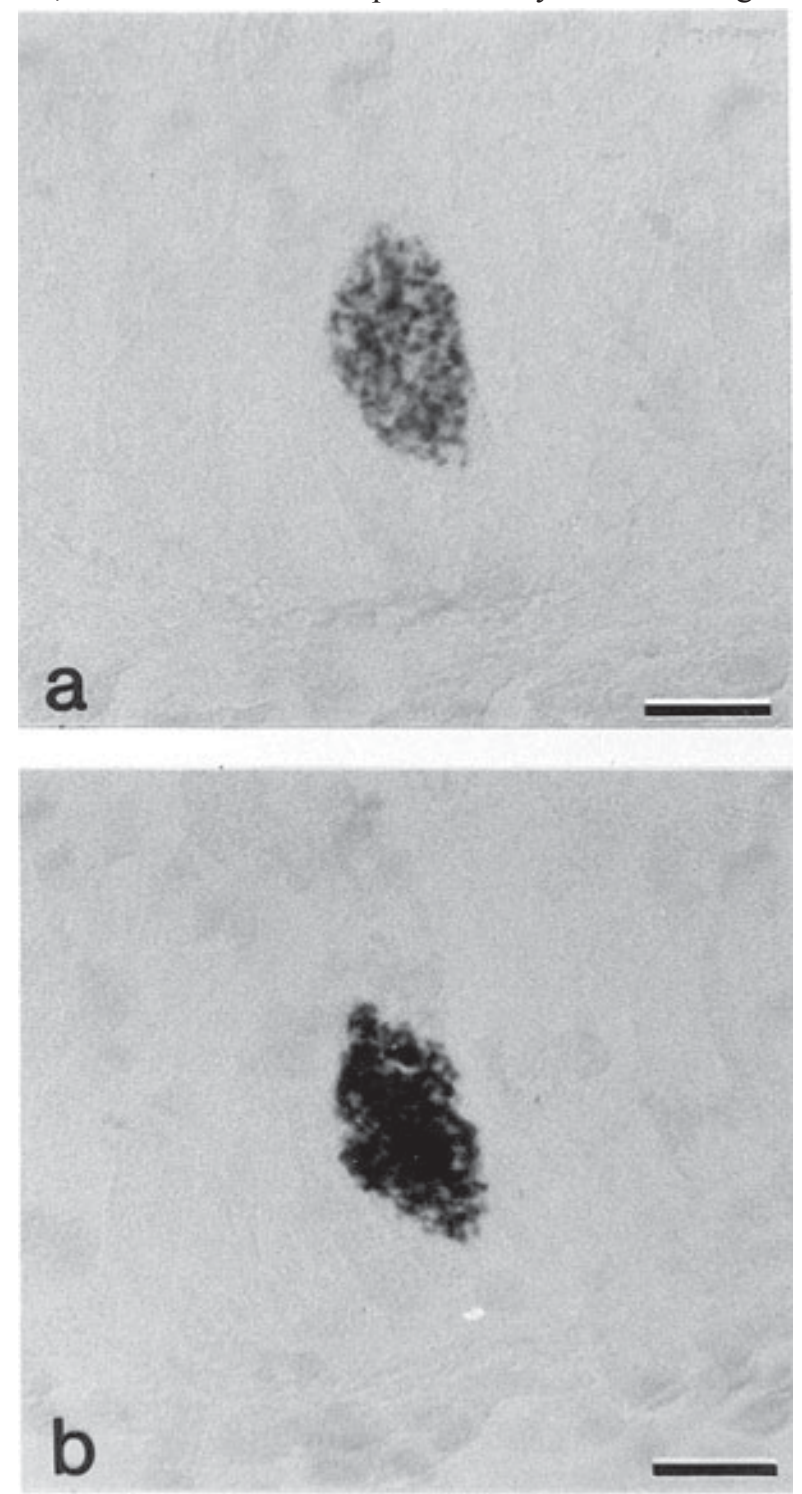

Fig. 3: indirect in situ polymerase chain reaction (PCR) of flagellar protein sequence with Trypanosoma cruzi amastigotes in infected murine cardiac tissue. a: control for indirect in situ PCR (Taq DNA polymerase was omitted); b: indirect in situ PCR of FPS. Bars $=40$ $\mu \mathrm{m}$ 
with this method. False positive results after direct in situ PCR, caused by primer-independent but both Taq DNA polymerase and cycling dependent incorporation of digoxigenin-labeled nucleotides into cellular DNA, can result from DNA repair mechanisms and/or internal nonspecific priming (Long et al. 1993).

The efficiency of DNA amplification is decreased in tissue sections in comparison to fluid phase PCR (Komminoth et al. 1992, Komminoth \& Long 1992, Long et al. 1993, O'Leary et al. 1994). However, in situ PCR has the advantage of localizing target sequences within tissue. Our results suggest that indirect in situ PCR provides an additional method for detecting low copy sequences. In situ hybridization alone is a useful technique to detect parasite-specific sequences - prior amplification using in situ PCR can greatly enhance this for certain low-copy sequences. Thus, it may be a useful tool to study the immunopathology of chronic chagasic cardiomyopathy. Additionally, the use of similar techniques has been used to detect other infectious organisms in the clinical setting - future studies are needed to develop such techniques to assist the clinician with the molecular detection of $T$. cruzi.

\section{ACKNOWLEDGEMENTS}

To Dr Heping Yan for technical assistance, to Dr Willi Honegger and Dr BJ Bogitsh for assistance with microscopy.

\section{REFERENCES}

Boshoff C, Schulz TF, Kennedy MM, Graham AK, Fisher C, Thomas A, McGee JO, Weiss RA, O'Leary JJ 1995. Kaposi's sarcoma-associated herpesvirus infects endothelial and spindle cells. Nat Med 1: 1274-1278.

Brener Z 1973. Biology of Trypanosoma cruzi. Annu Rev Microbiol 27: 347-382.

Brener Z, Gazzinelli RT 1997. Immunological control of Trypanosoma cruzi infection and pathogenesis of Chagas' disease. Int Arch Allergy Immunol 114: 103-110.

Chen J, Rauch CA, White JH, Englund PT, Cozzarelli NR 1995. The topology of the kinetoplast DNA network. Cell 80: 61-69.

Degrave W, Fragos SP, Britto C, van Heuverswyn H, Kidane GZ, Cardoso MA, Mueller RU, Simpson L, Morel L 1998. Peculiar sequence organization of kinetoplast DNA minicircles from Trypanosoma cruzi. Mol Biochem Parasitol 27: 63-70.

Komminoth P, Long AA 1992. In-situ polymerase chain reaction. Virchows Archiv B Cell Pathol 64: 67-73.

Komminoth P, Long AA, Ray A, Wolfe HJ 1992. In situ polymerase chain reaction detection of viral DNA, single-copy genes, and gene rearrangements in cell suspensions and cytospins. Diag Mol Pathol 1:85-97.
Lane JE, Olivares-Villagomez D, Vnencak-Jones, C, McCurley TL, Carter CE 1997. Detection of Trypanosoma cruzi with the polymerase chain reaction and in situ hybridization in infected murine cardiac tissue. Am J Trop Med Hyg 56: 588-595.

Larsson LI, Hougaard DM 1993. Sensitive detection of rat gastrin mRNA by in situ hybridization with chemically biotinylated oligodeoxynucleotides: Validation, quantitation, and double-staining studies. J Histochem Cytochem 41: 157-163.

Long AA, Komminoth P, Lee E, Wolfe HJ 1993. Comparison of indirect and direct in-situ polymerase chain reaction in cell preparations and tissue sections. Histochem 99: 151162.

Moser DR, Kirchhoff LV, Donelson JE 1989. Detection of Trypanosoma cruzi by DNA amplification using the polymerase chain reaction. J Clin Microbiol 27: 1477-1482.

Nuovo GJ 1994. PCR in Situ: Protocols and Applications, 2nd ed., Raven Press, New York.

O'Leary JJ, Browne G, Johnson MI, Landers RJ, Crowley M, Healy I, Street JT, Pollock AM, Lewis FA, Andrew A 1994. PCR in situ hybridization detection of HPV 16 in fixed CaSki and fixed SiHa cell lines. J Clin Pathol 47: 933938.

Olivares-Villagomez D, McCurley TL, Vnencak-Jones C, Correa-Oliveira R, Colley DG, Carter CE 1998. Polymerase chain reaction amplification of three different Trypanosoma cruzi DNA sequences from human chagasic cardiac tissue. Am J Trop Med Hyg 59: 563-570.

Palomino SA, Aiello VD, Higuchi ML 2000. Systematic mapping of hearts from chronic chagasic patients: the association between the occurrence of histopathological lesions and Trypanosoma cruzi antigens. Ann Trop Med Parasitol 94: 571-579.

Prata A 2001. Clinical and epidemiological aspects of Chagas disease. The Lancet Infectious Diseases 1: 92-100.

Sällström JF, Zehbe I, Alemi M, Wilander E 1993. Pitfalls of in situ polymerase chain reaction (PCR) using direct incorporation of labelled nucleotides. Anticancer Res 13:11531154.

Tanowitz HB, Kirchoff LV, Simon D, Morris SA, Weiss LM, Wittner M 1992. Chagas' disease. Clin Microbiol Rev 5: 400-419.

Tarleton RL, Zhang L, Downs MO 1997. “Autoimmune rejection" of neonatal herat transplants in experimental Chagas disease is a parasite-specific response to infected host tissue. Proc Natl Acad Sci USA 94: 3932-3937.

Van Voorhis WC, Eisen H 1989. Fl-160. A surface antigen of Trypanosoma cruzi that mimics mammalian nervous tissue. J Exp Med 169: 641-652.

Van Voorhis WC, Schlekewy L, Trong HL 1991. Molecular mimicry by Trypanosoma cruzi: the Fl-160 epitope that mimics mammalian nerve can be mapped to a 12 -amino acid peptide. Proc Natl Acad Sci USA 88: 5993-5997. 